\title{
A CASE OF MISSING IUCD
}

Sreeja Rani. V. R

1. Associate Professor. Department of Obstetrics \& Gynecology, SUT Academy of Medical Sciences.

\section{CORRESPONDING AUTHOR}

Dr. Sreeja Rani. V.R,

TC 36/472, APRA-88,

Lavanya, Palkulangara,

Pettah.P. 0, Trivandrum- 695024.

E-mail: sreeja546@yahoo.co.in

Ph: 00919447657081

ABSTRACT: Intrauterine device is a popular method of contraception in India. Though relatively safe, it may cause dangerous complications like uterine perforation. Here a case is presented where asymptomatic perforation occurs in a lactating woman with contraceptive found in the peritoneal cavity.

KEYWORDS: Intrauterine device, perforation, uterine.

INTRODUCTION:-Intrauterine contraceptive device is a reversible method of contraception used by about 160 million women worldwide.[1] It can be used for long periods and is highly effective. It does not interfere with lactation and because of this, many lactating women prefer intrauterine devices for contraception. Although relatively safe, it can be associated with problems like irregular menses, infections and rarely it can lead on to uterine perforations and associated complications.

CASE REPORT:A 22 year old woman presented with mild lower abdominal pain and dysuria one week following a copper intrauterine contraceptive device insertion. The symptoms had started after the insertion. She was a primipara with a full term vaginal delivery two and a half months back. She was fully lactating. Her menses had resumed two weeks back and the IUCD(Copper T 380A) was inserted on the seventh day of her periods. There was no bleeding per vagina during and after the insertion.

On examination, her general condition was good. The abdomen was soft and there was no tenderness or guarding. On speculum examination, the thread of the IUCD was missing. Pelvic examination revealed a smaller than normal uterus with tender anterior and left fornices. She was then sent for ultrasound examination which showed the contraceptive device close to the anterior uterine wall with suspected embedding of the device in the myometrium. Attempt was made to remove the IUCD with curette but failed. The patient was counseled regarding the risk of uterine perforation and with an informed consent, a hysteroscopy was performed the next day. No part of the IUCD could be detected by the hysteroscope. It was then proceeded by a laparotomy. The IUCD was found lying between the bladder and the anterior wall of the uterus. A scar, $<5 \mathrm{~mm}$ was found near the uterine fundus anteriorly. There were no adhesions and the bladder was intact.

The postoperative period was uneventful and the patient was discharged on the fifth day. She was explained the risk of uterine rupture during subsequent pregnancy and hence the need for routine antenatal examinations with sonographic follow-up. 
DISCUSSION:-The history of intrauterine devices starts with story of caravan drivers using intrauterine stones to prevent pregnancies in their camels during long journeys. In 1800s, small stem pessaries were used which were followed by small button like structures, Grafenberg ring, Ota ring, Margulies coil, the Lippe's loop, Saf-T-Coil and the Dalkon Shield. In 1970s, came the copper containing devices which were relatively safe and with lesser complications.

The intrauterine device used in our patient was $\mathrm{Cu}-\mathrm{T} 380 \mathrm{~A}$, a $\mathrm{T}$ shaped device (figure 1) with a polyethylene frame holding $380 \mathrm{~mm} 2$ of exposed surface of copper.

The side effects of copper containing devices include irregular menses, dysmennorhoea, infection, pregnancy with intrauterine device in situ and uterine perforation. Perforation is uncommon but a dangerous complication with a reported incidence of 0.1-3 per 1000 insertions.[2] Zakin et al made an analysis of 356 cases of uterine perforation due to intrauterine device insertion. Of these, in 53 cases $(15 \%)$, the contraceptive device was found to intrude upon the intestinal tract with bowel perforations and in 6 cases, the device was found in bladder.[3] There has been a report of intrauterine device with uterine perforation causing intestinal obstruction 31 years after insertion.[4] There has also been a report of intrauterine device recovered 39 years after insertion causing chronic renal disease as a result of vesicovaginal fistula formation after uterine perforation.[5] Ileal penetration has been reported as early as four weeks after insertion.[6]

In an analysis of risk factors associated with uterine perforation by intrauterine devices by Caliskan et al, the risk of perforation was found to be significantly increased if the intrauterine device was inserted before 6 months of delivery. Increased parity was found to cause $96 \%$ decrease in the perforation risk.[7] During lactation the uterus is soft in consistency, involuted and contractile with decreased level of oestrogens. Also the beta endorphins during lactation are increased masking the pain of uterine perforation.[8]

The management of displaced intrauterine devices has been controversial as whether to remove or not to remove an asymptomatic intrauterine device in the peritoneal cavity by subjecting the patient to the risks of laparotomy. However, WHO recommends removal of the device as soon as possible after the diagnosis has been made as copper containing devices are found to cause adhesions.[9] Removal can also prevent intestinal and other visceral complications.

During the subsequent pregnancy, the patient has to be followed up with sonographic examination to rule out thinning of the scar at the perforation site or silent uterine rupture. There are case reports of uterine defects in pregnancy following previous perforation, detected by ultrasound examination and treated successfully.[10]

CONCLUSIONS: After insertion of intrauterine contraceptive device, the woman has to be followed up after a few weeks to ascertain the correct positioning. There is increased risk of uterine perforation if the intrauterine device is inserted in the early months following delivery when the woman is fully lactating. To avoid visceral complications, the contraceptive device should be removed once it enters the peritoneal cavity after perforation.

\section{REFERENCES:}


1. Peterson HB, Kurtis KM. Long acting methods of contraception. N Engl J Med 2005;353:2169-2175.

2. Boyon C, Giraudet G, Guerin Du Masgenet B, Lucot JP, Goeusse P, Vinatier D. Diagnosis and management of uterine perforations after intrauterine device insertion: A report of 11 cases. Gynecol Obstet Fertil. 2012 July [ E pub ahead of print ].

3. Zakin D, Stern WZ, Rosenblatt R. Complete and partial uterine perforation and embedding following insertion of intrauterine devices. I.Classification, complications, mechanism, incidence and missing string. Obstet Gynecol Surv 1981;36(7):335-53.

4. Brar R, Doddi S, Ramasamy A, Sinha P. A forgotten migrated intrauterine contraceptive device is not always innocent: A case report. Case report Med 2010. 2010:740642.

5. Karsmakers R, Weiss-Potters AE, Buijs G, Joustra EB. Chronic kidney disease after vesico-vaginal stone formation around migrated intrauterine device. BMJ Case Rep 2010; 2010:bcr1220092547.

6. Chen CP, Hsu TC, Wang W. Ileal penetration by a Multiload-Cu 375 intauterine contraceptive device: a case report with review of literature. Contraception 1998;58(5):295-304.

7. Caliskan E, Ozturk N, Dilbaz BO, Dilbaz S. Analysis of risk factors associated with uterine perforation by intrauterine devices. Eur J Contracept Reprod Health Care 2003;8(3):150-5.

8. Andersson K, Ryde-Blomqvist E, Lindell K, Odlind V, Milsom I. Perforations with intrauterine devices. Report from a Swedish survey. Contraception 1998;57:251-5.

9. WHO. Mechanism of action, safety and efficacy of intrauterine devices. Geneva: World Health Organization, 1987:48.

10. Cheng PJ, Chueh HY, Soong YK. Sonographic diagnosis of a uterine defect in a pregnancy at 6 weeks' gestation with a history of curettage. Ultrasound Obstet Gynecol 2003;21:501-503.

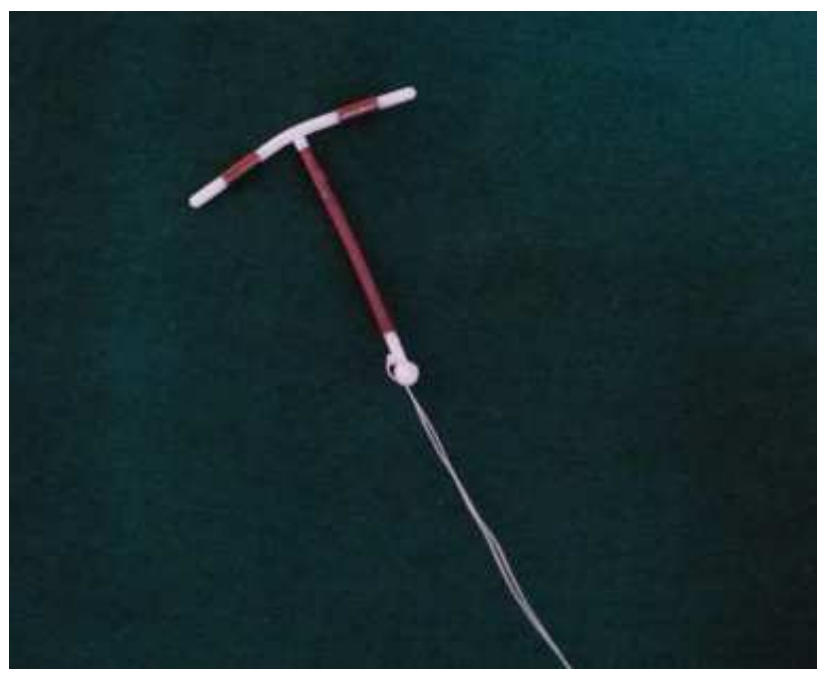

Figure 1- copper T $380 \mathrm{~A}$ 